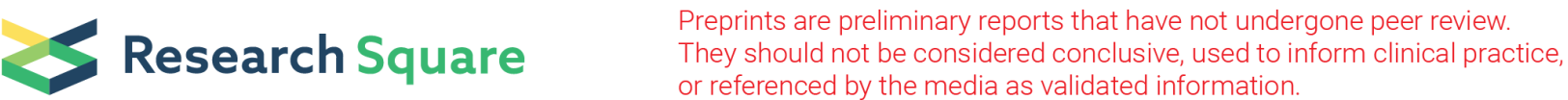

\section{Pharmacodynamic Study of QingFei Paidu Decoction in the Treatment of Acute Respiratory Distress Syndrome Caused by Coronavirus Disease- 2019 (COVID-19)}

\section{Zhixian He}

Southwest Jiaotong University

Xinyv Wang

Southwest Jiaotong University

Xing Wang ( $\sim$ wshing@263.net)

Southwest Jiaotong University https://orcid.org/0000-0002-6380-7958

Jinyue Wang

Southwest Jiaotong University

Research

Keywords: QingFei Paidu Decoction, COVID-19, ARDS, Pharmacodynamic

Posted Date: May 26th, 2021

DOl: https://doi.org/10.21203/rs.3.rs-552799/v1

License: (c) (i) This work is licensed under a Creative Commons Attribution 4.0 International License.

Read Full License 


\section{Abstract}

Background: The outbreak of the Coronavirus Disease-2019 (COVID-19) has threatened the public health of the world, and may eventually lead to acute respiratory impoverishment syndrome (ARDS). ARDS is a clinical syndrome caused by intrapulmonary or extrapulmonary reasons, which has complex pathogenesis and high mortality rate, it's also one of the important factors in death from the 2019 novel coronavirus (2019-nCoV) epidemic. It has been reported that traditional Chinese medicine (TCM) can exert a good effect in the process of treatment. The present study aimed to observe the protective effects of TCM formula Qingfei Paidu Decoction (QFPD) on ARDS rats and explore the pharmacodynamic mechanism of the compound.

Methods: 24 male rats were randomly divided into 4 groups $(n=6)$, blank control group, model group, QFPD group $\left(18.6 \mathrm{~g} \cdot \mathrm{kg}^{-1} \cdot \mathrm{d}^{-1}\right)$ and dexamethasone group $\left(2 \mathrm{mg} \cdot \mathrm{kg}^{-1} \cdot \mathrm{d}^{-1}\right)$. Blank control group rats were given saline, whereas other groups were injected with oleic acid (OA) and lipopolysaccharide (LPS) successively to establish ARDS model, and observed the behavioral performance of rats after model building. The morphological changes of lung tissue under optical microscope were observed; rat lung index (LI) and lung permeability index (LPI) were measured; blood $\mathrm{PH}$, partial arterial oxygen pressure $\left(\mathrm{PaO}_{2}, \mathrm{mmHg}\right)$, partial arterial carbon dioxide pressure $\left(\mathrm{PaCO}_{2}, \mathrm{mmHg}\right)$, arterial oxygen saturation $\left(\mathrm{SaO}_{2}\right)$ were measured by blood gas analyzer; the levels of tumor necrosis factor-a (TNF-a), interleukin (IL-1 $\beta$, IL6, IL-8, IL-10), thromboxane $\mathrm{B}_{2}\left(\mathrm{TXB}_{2}\right)$, 6-keto-prostaglandin F1a (6-keto-PGF1a), kerbs von lungren 6 antigen (KL-6), C-reactive protein (CRP), and the expression of superoxide dismutase (SOD) were measured via test kit.

Results: Compared with the model group, the two treatment groups could improve the respiratory and lung injury in rats, and could restore the expression levels of thromboxane, various cytokines and protein to varying degrees.

Conclusions: QFPD and dexamethasone have protective effects on ARDS rats induced by jointly injecting OA and LPS, and QFPD has the better effect in between. These may be related to reducing the expression levels of IL-1 $\beta$, IL-6, IL-8, TNF- $a, C R P, T X B_{2}, K L-6$, and increasing the contents of IL-10, 6Keto-PGF1a and SOD vitality in the body.

\section{Background}

The acute respiratory distress syndrome (ARDS) is a clinical syndrome of acute lung injury characterized by acute onset of noncardiogenic pulmonary oedema, respiratory distress and refractory hypoxemia. ARDS most likely to occur in the case of pneumonia, sepsis, aspiration of stomach contents, or severe trauma ${ }^{[1]}$. Its pathogenesis is complex, in which endothelial injury, increased vascular permeability, and imbalance in the expression of inflammatory factors play an important role in the pathogenesis ${ }^{[2]}$. 
In this 2019 novel coronavirus (2019-nCoV) epidemic, some severe and critical COVID-19 patients meet the ARDS Berlin definition ${ }^{[3]}$. As one of the clinical features of COVID-19, ARDS is also a major cause of mortality associated with COVID-19 disease ${ }^{[4]}$. Qingfei Paidu Decoction (QFPD) is recommended by the National Health Commission and the State Administration of Traditional Chinese Medicine (TCM) for the treatment of COVID-19 pneumonia. The obtained universal prescription has curative effect on patients with mild, moderate and severe COVID-19 pneumonia, and the total effective rate can reach more than $90 \%{ }^{[5]}$. And studies have shown that the earlier the interventional treatment of QFPD the better the recovery effect, the shorter the virus shedding time, the shorter the hospital stay and the duration of the

disease ${ }^{[6]}$. A report in the United Kingdom pointed out that according to its clinical trials, dexamethasone is effective for patients with severe COVID-19. It can reduce deaths of patients who require ventilation by about one-third, but it has no obvious effect on mild to moderate patients ${ }^{[7]}$.

TCM has played a very good role in the medical service for COVID-19, this study was conducted to explore the mechanism of QFPD on ARDS, in order to provide a theoretical basis for QFPD in the treatment of COVID-19.

\section{Materials And Methods}

\section{Materials}

QFPD was composed with the following 21 Traditional Chinese Herbs: Gypsum Fibrosum 30g, Ephedrae Herba 9g, Glycyrrhizae Radix et Rhizoma Praeparata Cum Melle 6g, Armeniacae Semen Amarum 9g, Cinnamomi Ramulus 9g, Alismatis Rhizoma 9g, Polyporus 9g, Atractylodis Macrocephalae Rhizoma 9g, Poria 15g, Bupleuri Radix 16g, Scutellariae Radix 6g, Pinelliae Rhizoma Praeparatumcum Zingibere et Alumine 9g, Zingiberis Rhizoma Recens 9g, Asteris Radix et Rhizoma 9g, Farfarae Flos 9g, Belamcandae Rhizoma 9g, Asari Radix et Rhizoma 6g, Dioscoreae Rhizoma 12g, Aurantii Fructus Immaturus 6g, Citri Reticulatae Pericarpium 6g, Pogostemonis Herba $9 \mathrm{~g}$ (Table 1). All medicinal materials were purchased from Beijing Tongrentang Pharmacy and made into Chinese medicine decoction (QFPD, 1.407g crude medicine $\cdot \mathrm{mL}^{-1}$ ). Dexamethasone and lipopolysaccharide were purchased from Beijing Solarbio Technology Co., Ltd. (Beijing, China); pure OA was purchased from Chengdu Alfa Biotechnology Co., Ltd. (Chengdu, China). TNF-a, IL-1 $\beta$, IL-6, IL-8 and IL-10 enzyme-linked immunosorbent assay (ELISA) kits were purchased from Excell Bio Co., Ltd. (Shanghai, China); TXB2, 6-keto-PGF1a, KL-6 ELISA kits were purchased from Shanghai Jianglai Biotechnology Co., Ltd. (Shanghai, China); SOD, CRP detection kits were purchased from Nanjing Jiancheng Bioengineering Institute, (Nanjing, China), HE staining kit was purchased from Beijing Solarbio Technology Co., Ltd. (Beijing, China). 
Table 1

Components of QFPD.

\begin{tabular}{|c|c|c|c|}
\hline Chinese Name & Botanical Origin (Family) & Part Used & Content(g) \\
\hline Sheng shi gao & Gypsum Fibrosum (Anhydrite) & / & 30 \\
\hline Ma huang & Ephedra sinica Stapf (Ephedraceae) & Stem & 9 \\
\hline Zhi gan cao & Glycyrrhiza uralensis Fisch. (Leguminosae) & Root & 6 \\
\hline Ku xing ren & Prunus armeniaca L. (Rosaceae) & seed & 9 \\
\hline Gui zhi & Cinnamomum cassia Presl (Lauraceae) & Burgeon & 9 \\
\hline Ze xie & Alisma orientale (Sam.) Juzep. (Alisaceae) & Stem & 9 \\
\hline Zhu ling & Polyporus umbellatus (Pers.) Fries (Polyporaceae) & Sclerotium & 9 \\
\hline Bai zhu & Atractylodes macrocephala Koidz. (Compositae) & Root & 9 \\
\hline Fu ling & Poria $\operatorname{cocos}$ (Schw.) Wolf (Polyporaceae) & Sclerotium & 15 \\
\hline Chai hu & Bupleurum chinense DC. (Umbelliferae) & Root & 16 \\
\hline Huang qin & Scutellaria baicalensis Georgi (Labiatae) & Root & 6 \\
\hline Jiang ban xia & Pinellia ternata (Thunb.) Breit. (Araceae) & Stem & 9 \\
\hline Sheng jiang & Zingiber officinale Rosc. (Zingiberaceae) & Root & 9 \\
\hline Zi wan & Aster tataricus L.f. (Compositae) & Root & 9 \\
\hline Kuan dong hua & Tussilago farfara L. (Compositae) & Bud & 9 \\
\hline She gan & Belamcanda chinensis (L.) DC. (Iridaceae) & Root & 9 \\
\hline Xi xin & Asarum sieboldii Miq.(Aristolochiaceae) & Root & 6 \\
\hline Shan yao & Dioscorea opposite Thunb. (Dioscoreaceae) & Root & 12 \\
\hline Zhi shi & Citrus aurantium L. (Rutaceae) & Fruit & 6 \\
\hline Chen pi & Citrus reticu1ata B1 anco (Rutaceae) & peel & 6 \\
\hline Huo xiang & Pogostemon cablin (Blanco) Benth. (Labiatae) & Stem & 9 \\
\hline
\end{tabular}

\section{Animals and experimental design}

24 SD male rats, aged 6-8 weeks, weighting $(200 \pm 20) \mathrm{g}$, were purchased from Chengdu Dashuo Experimental Animal Co., Ltd. (Chengdu, China) [ license number: SCXK (Sichuan) 2019-030], and fed in the clean animal room of the Experimental Center of Chinese People's Liberation Army Western Theater General Hospital. All rats were given the same standards of ordinary feed and free drinking water. After adaptive feeding for one week, 24 experimental rats were randomly divided into 4 groups: blank control group, model group, QFPD group and dexamethasone group with 6 rats in each group. 
The blank control group was injected with $0.9 \%$ saline via tail vein $(0.05 \mathrm{ml} / \mathrm{kg}$ body weight), all other rats were first injected with pure OA $(0.05 \mathrm{ml} / \mathrm{kg}$ body weight) via the tail vein, then injected with LPS $(2.5 \mathrm{mg} / \mathrm{ml}, 2.5 \mathrm{mg} / \mathrm{kg}$ body weight) slightly above the first injection position 30 minutes later. According to the conversion results (The dose of a $200 \mathrm{~g}$ rat is equal to 6.17 times the dose of a $70 \mathrm{~kg}$ adult human.), the rats in QFPD group received $18.6 \mathrm{~g} / \mathrm{kg}$ by gavage once a day $(18.6 \mathrm{~g} \cdot \mathrm{kg}-1 \cdot \mathrm{d}-1$, crude drug ); the rats in dexamethasone group were injected intraperitoneally at a dose of $2 \mathrm{mg} / \mathrm{kg}$ once a day $(2 \mathrm{mg} \cdot \mathrm{kg}-1 \cdot \mathrm{d}-1)$; the rats in blank control group and model group were given $2.6 \mathrm{ml} / 200 \mathrm{~g}$ distilled water by gavage once a day. The administration was continued for 7 days.

\section{Sample collection}

The rats were fasted after the administration on the 7th day, but water was allowed. On the 8th day, all rats were first weighed and then anesthetized by intraperitoneal injection of $4 \%$ chloral hydrate $(0.8 \mathrm{ml} / 100 \mathrm{~g})$. The blood was collected from the abdominal aorta, and some blood samples were quickly sent for testing within 10 minutes; the remaining samples were allowed to stand at room temperature for 30 minutes and then sent to centrifugation $\left(4000 \mathrm{rpm}, 4^{\circ} \mathrm{C}\right)$ for 15 minutes to separate the serum, the serum was stored at $-80^{\circ} \mathrm{C}$ for testing. The rat's chest was opened, and the intact lungs were quickly removed with a trachea of sufficient length retained. The blood and tissue fluid on the lung surface were absorbed by clean filter paper, and the weight of wet lung was measured. The right lung was ligated, and fully exposed the left lung, then infused $4 \mathrm{ml}$ of normal saline into the main bronchus. After the left lung is filled, slowly withdraw the syringe to obtain the bronchoalveolar lavage fluid (BALF), and the lavage was repeated 2 times. The recycled BALF was collected at $-80^{\circ} \mathrm{C}$ for standby application. One lobe of the right lung was randomly taken, and the air in it was pumped back, then soaked the lobe in formalin solution ( $4 \%$ formaldehyde), and stored it at room temperature for measurement.

\section{Examination of $\mathrm{LI}, \mathrm{LPI}, \mathrm{pH}, \mathrm{PaO}_{2}, \mathrm{PaCO}_{2}$ and $\mathrm{SaO}_{2}$}

The arterial blood was detected with an automatic blood gas analyzer within 10 minutes to determine the $\mathrm{pH}, \mathrm{PaO}_{2}, \mathrm{PaCO}_{2}$ and $\mathrm{SaO}_{2}$ values. The $\mathrm{LI}$ was calculated based on the wet lung mass: $\mathrm{LI}=$ whole lung wet mass $(\mathrm{mg}) /$ body mass $(\mathrm{g})$. Put the frozen BALF and serum into a $4^{\circ} \mathrm{C}$ environment in advance to thaw, and the Bradford method was used to determine the protein concentration of the serum and the BALF, LPI = BALF protein content / serum protein content.

\section{Examination of TNF-a, IL-1 $\beta$, IL-8, IL-6, IL-10, TXB 2 , 6-keto- PGF1a, KL-6, CRP and SOD}

An appropriate amount of serum and BALF was taken, followed by loading and treatment in strict accordance with instructions of the ELISA kit and SOD, CRP detection kits. The levels of TNF- $a$, IL-1 $\beta$, IL-8, IL-6, IL-10, TXB 2 , 6-keto-PGF1a, KL-6, CRP and SOD vitality in each sample were calculated.

\section{Histochemistry analysis of lung tissue}


The lung tissue of 2.4 was embedded in paraffin, sectioned $(5 \mu \mathrm{m})$ and stained with hematoxylin and eosin (HE) for microscopic view. Images were collected under multiple of 400 for pathological observation.

\section{Statistical analysis}

The SPSS 25.0 software was used to carry out statistical analysis on the experimental result data, and all the data were expressed as mean \pm standard deviation $( \pm s)$. The measurement data were all tested by one-way ANOVA. After pairwise comparison, LSD (Least-Significant Difference) test analysis is selected for those with uniform variance, and Tamhane T2 test analysis is selected for those with uneven variance. $P<0.05$ was considered to have a significant difference.

\section{Results}

\section{Results of lung pathological changes of rats}

HE staining was performed to evaluate the pathological changes of lungs in the different groups. As seen in Fig. 1, the alveolar structure in blank control group was complete without inflammatory cell infiltration, and the alveolar spacing was normal. In the model group, the alveolar septum was significantly thickened, and the alveolar wall was destroyed as well as the lymphocytes in the local alveolar cavity increased obviously. The inflammatory cells infiltrated significantly, mainly distributed in the interstitium of the alveoli and around the bronchus. However, both treatment groups have improved with inflammatory cell infiltration and alveolar spacing, among the two groups, the improvement was better with QFPD.

\section{Measurement results of LI and LPI in each group}

As shown in Table 2. The LI and LPI values of model group were significantly increased $(P<0.01)$ compared with those in blank control group, but they were obviously decreased in QFPD group compared with model group $(P<0.01)$. DXMS group could effectively reduce the $L P I$ value $(P<0.01)$ compared with that in model group, but there was no significant difference in $\mathrm{LI}$. The improvement effect was DXMS group > QFPD group.

Table 2

Comparison of rats $\mathrm{LI}$ and LPI in each group

\begin{tabular}{|lll|}
\hline Group & LI & LPI \\
\hline Blank control group & $6.13 \pm 0.32$ & $0.0045 \pm 0.0007$ \\
\hline Model group & $8.35 \pm 0.39^{\# \#}$ & $0.0081 \pm 0.0012^{\# \#}$ \\
\hline QFPD group & $7.37 \pm 0.35^{\star \star}$ & $0.0054 \pm 0.0011^{\star *}$ \\
\hline DXMS group & $8.01 \pm 0.44$ & $0.0050 \pm 0.0007^{\star *}$ \\
\hline
\end{tabular}


Compared with the blank control group, \# $\mathrm{P}<0.05$, \# $\mathrm{P}<0.01$; compared with the model group, ${ }^{\star} \mathrm{P}<0.05$, ** $P<0.01$

\section{Results of blood gas analysis}

As shown in Table 3, The results of blood gas analysis instrument showed that there was no significant difference in $\mathrm{pH}$ value between the groups $(\mathrm{P}>0.05)$. The $\mathrm{PaCO}_{2}$ value of model group was obviously higher than that of blank group $(\mathrm{P}<0.01)$, in terms of $\mathrm{PaO}_{2}$ and $\mathrm{SaO}_{2}$, the value of model group was significantly lower than those of the blank control group $(\mathrm{P}<0.01)$, especially for the $\mathrm{PaO}_{2}$.

The values of $\mathrm{PaCO}_{2}, \mathrm{PaO}_{2}$ and $\mathrm{SaO}_{2}$ were improved to varying degrees compared with those in model group $(P<0.05)$. The improvement effect of QFPD group was more obvious $(P<0.01)$, and the improvement effect was QFPD group > DXMS group.

Table 3

Comparison of blood gas analysis results in each group

\begin{tabular}{|lllll|}
\hline Group & $\mathrm{pH}$ & $\mathrm{PaCO}_{2}(\mathrm{mmHg})$ & $\mathrm{PaO}_{2}(\mathrm{mmHg})$ & $\mathrm{SaO}_{2}(\%)$ \\
\hline Blank control group & $7.38 \pm 0.01$ & $37.33 \pm 2.42$ & $94.83 \pm 3.13$ & $95.67 \pm 1.21$ \\
\hline Model group & $7.36 \pm 0.01$ & $57.83 \pm 1.60^{\# \#}$ & $69.17 \pm 1.72^{\# \#}$ & $91.33 \pm 1.51^{\# \#}$ \\
\hline QFPD group & $7.37 \pm 0.02$ & $51.00 \pm 2.00^{\star *}$ & $78.33 \pm 2.94^{\star *}$ & $95.00 \pm 1.79^{\star *}$ \\
\hline DXMS group & $7.36 \pm 0.01$ & $54.67 \pm 0.82^{\star *}$ & $72.83 \pm 1.72^{\star}$ & $94.33 \pm 1.21^{\star *}$ \\
\hline
\end{tabular}

Compared with the blank control group, \# $\mathrm{P}<0.05$, \# $\mathrm{P}<0.01$; compared with the model group, ${ }^{*} \mathrm{P}<0.05$, ** $\mathrm{P}<0.01$

\section{Expression results of TNF- $a$, IL-1 $\beta$, IL-6, IL-8 and IL-10 in BALF and serum}

As shown in Table 4, the level of TNF-a of model group was visibly increased in BALF and serum compared with that in blank control group ( $p<0.05$ in BALF, $P<0.01$ in serum), while the administration groups could reduce the concentration of TNF- $a$ in different degrees $(P<0.01$ in BALF, $P<0.01$ in serum), and the reduced degree of TNF-a in BALF was QFPD group > DXMS group; DXMS group > QFPD group in serum. 
Table 4

Comparison of BALF and serum TNF-a concentration results in each group $(\mathrm{pg} / \mathrm{mL})$

\begin{tabular}{|lll|}
\hline Group & TNF- $a$ in BALF & TNF- $a$ in serum \\
\hline Blank control group & $39.37 \pm 2.12$ & $173.13 \pm 11.73$ \\
\hline Model group & $56.30 \pm 6.83^{\#}$ & $214.76 \pm 13.81^{\# \#}$ \\
\hline QFPD group & $33.11 \pm 3.29^{\star \star}$ & $183.26 \pm 6.75^{\star \star}$ \\
\hline DXMS group & $38.86 \pm 3.22^{* \star}$ & $175.65 \pm 6.91^{\star \star}$ \\
\hline
\end{tabular}

Compared with the blank control group, \# $\mathrm{P}<0.05$, \# $\mathrm{P}<0.01$; compared with the model group, * $\mathrm{P}<0.05$, ** $\mathrm{P}<0.01$

As shown in Table 5, the concentration of serum and BALF IL-1 $\beta$ in model group was significantly higher than that in blank group ( $p<0.05$ in BALF, $p<0.01$ in serum). Compared with model group, the IL-1 $\beta$ concentration could be reduced effectively in administration groups ( $p<0.05$ in BALF, $p<0.01$ in serum). The reduced degree of IL-1 $\beta$ in BALF was QFPD group > DXMS group, and in serum was QFPD group > DXMS group.

Table 5

Comparison of BALF and serum IL-1 $\beta$ concentration results in each group $(\mathrm{pg} / \mathrm{ml})$

\begin{tabular}{|lll|}
\hline Group & IL-1 $\beta$ in BALF & IL-1 $\beta$ in serum \\
\hline Blank control group & $2.06 \pm 1.10$ & $39.13 \pm 4.73$ \\
\hline Model group & $25.16 \pm 9.10^{\#}$ & $67.16 \pm 4.10^{\# \#}$ \\
\hline QFPD group & $6.62 \pm 3.78^{\star}$ & $34.54 \pm 3.39^{\star *}$ \\
\hline DXMS group & $9.00 \pm 6.20^{\star}$ & $39.31 \pm 7.66^{\star *}$ \\
\hline
\end{tabular}

Compared with the blank control group, \# $\mathrm{P}<0.05$, \# $\mathrm{P}<0.01$; compared with the model group, $* \mathrm{P}<0.05$, ** $\mathrm{P}<0.01$

As shown in Table 6, the concentration of serum and BALF IL-6 in model group was distinctly increased compared with that in blank control group $(\mathrm{P}<0.01$ in BALF, $\mathrm{P}<0.05$ in serum). Compared with model group, the level of IL-6 in treated groups was obviously decreased ( $P<0.01$ in BALF, $P<0.05$ in serum). The decrease degree of QFPD group was more obvious, and the reduced degree were both QFPD group $>$ DXMS group. 
Table 6

Comparison of BALF and serum IL-6 concentration results in each group $(\mathrm{pg} / \mathrm{ml})$

\begin{tabular}{|lll|}
\hline Group & IL-6 in BALF & IL-6 in serum \\
\hline Blank control group & $70.49 \pm 6.62$ & $118.58 \pm 24.17$ \\
\hline Model group & $170.36 \pm 18.90^{\# \#}$ & $533.79 \pm 155.87^{\#}$ \\
\hline QFPD group & $87.81 \pm 8.67^{\star \star}$ & $183.03 \pm 95.44^{*}$ \\
\hline DXMS group & $117.19 \pm 17.18^{\star \star}$ & $223.21 \pm 62.38^{\star}$ \\
\hline
\end{tabular}

Compared with the blank control group, \# $\mathrm{P}<0.05$, \# $\mathrm{P}<0.01$; compared with the model group, * $\mathrm{P}<0.05$, $\star * \mathrm{P}<0.01$

As shown in Table 7, the concentration of serum and BALF IL-8 in rats in model group was noticeably higher than that in blank control group $(P<0.01)$. Compared with the model group, the IL-8 concentration was markedly decreased in the administration groups $(P<0.01)$, the reduced degree was more obvious in the QFPD group, and the order were both QFPD group > TC group.

Table 7

Comparison of BALF and serum IL-8 concentration results of rats in each group $(\mathrm{pg} / \mathrm{ml})$

\begin{tabular}{|lll|}
\hline Group & IL-8 in BALF & IL-8 in serum \\
\hline Blank control group & $57.52 \pm 1.34$ & $70.30 \pm 1.50$ \\
\hline Model group & $88.78 \pm 1.26^{\# \#}$ & $112.20 \pm 4.08^{\# \#}$ \\
\hline QFPD group & $71.70 \pm 6.28^{\star \star}$ & $85.93 \pm 4.65^{\star *}$ \\
\hline DXMS group & $69.21 \pm 5.80^{\star \star}$ & $82.16 \pm 1.48^{\star \star}$ \\
\hline
\end{tabular}

Compared with the blank control group, \# $\mathrm{P}<0.05$, \# $\mathrm{P}<0.01$; compared with the model group, * $\mathrm{P}<0.05$, $\star * P<0.01$

As shown in Table 8, in BALF, the IL-10 concentration of model group was obviously lower than that of blank control group $(P<0.01)$. Compared with model group, the IL-10 concentration of QFPD group and DXMS group were significantly increased $(P<0.01)$, the degree of increase was QFPD group $>$ DXMS group. In the rat serum, compared with blank group, the IL-10 concentration of model group was markedly lower $(P<0.01)$, while the IL-10 concentration of QFPD group and DXMS group was significantly increased compared with that in model group $(P<0.05)$, and the effects were almost the same. 
Table 8

Comparison of BALF and serum IL-10 concentration results of rats in each group $(\mathrm{pg} / \mathrm{ml})$

\begin{tabular}{|lll|}
\hline Group & IL-10 in BALF & IL-10 in serum \\
\hline Blank control group & $20.33 \pm 3.56$ & $87.47 \pm 16.79$ \\
\hline Model group & $12.29 \pm 3.96^{\# \#}$ & $44.70 \pm 6.22^{\# \#}$ \\
\hline QFPD group & $20.72 \pm 3.52^{\star \star}$ & $81.87 \pm 20.12^{*}$ \\
\hline DXMS group & $19.69 \pm 2.07^{\star \star}$ & $80.81 \pm 19.21^{\star}$ \\
\hline
\end{tabular}

Compared with the blank control group, \# $\mathrm{P}<0.05$, \# $\mathrm{P}<0.01$; compared with the model group, ${ }^{*}<<0.05$, ** $P<0.01$

\section{Expression results of $\mathrm{TXB}_{2}, 6-k e t 0-P G F 1 a, \mathrm{KL}-6$ in BALF and serum}

As shown in Table 9, the $\mathrm{TXB}_{2}$ concentration in model group was noticeably higher than that in blank control group $(P<0.01)$, while it decreased significantly in QFPD group and DXMS group compared with model group in BALF $(P<0.01)$, among which QFPD group decreased more significantly than DXMS group; in rat serum, there was no significant difference between the model group and administration groups $(P>0.05)$.

Table 9

Comparison of BALF and serum $\mathrm{TXB}_{2}$ concentration results of rats in each group $(\mathrm{pg} / \mathrm{ml})$

\begin{tabular}{|lll|}
\hline Group & $\mathrm{TXB}_{2}$ in BALF & $\mathrm{TXB}_{2}$ in serum \\
\hline Blank control group & $19.58 \pm 2.07$ & $19.58 \pm 2.73$ \\
\hline Model group & $43.19 \pm 7.09^{\# \#}$ & $49.74 \pm 14.56^{\#}$ \\
\hline QFPD group & $32.49 \pm 4.97^{\star \star}$ & $35.84 \pm 8.00$ \\
\hline DXMS group & $34.06 \pm 6.28^{\star *}$ & $39.34 \pm 11.26^{*}$ \\
\hline
\end{tabular}

Compared with the blank control group, \# $\mathrm{P}<0.05$, \# $\mathrm{P}<0.01$; compared with the model group, ${ }^{*} \mathrm{P}<0.05$, $\star \star P<0.01$

As shown in Table 10, The concentration of 6- keto-PGF1a in model group was significantly lower than that in blank control group in rat BALF and serum $(P<0.01)$. Only QFPD group could effectively reduce the concentration of 6- keto-PGF1a in BALF $(P<0.05)$, and neither the QFPD group nor the DXMS group could effectively reduce the concentration of 6-keto-PGF1a in serum $(P<0.05)$. 
Table 10

Comparison of BALF and serum 6- keto-PGF1a concentration results of rats in each group $(\mathrm{pg} / \mathrm{ml})$

\begin{tabular}{|lll|}
\hline Group & 6- keto-PGF1a in BALF & 6- keto-PGF1a in serum \\
\hline Blank control group & $186.27 \pm 28.11$ & $177.92 \pm 14.79$ \\
\hline Model group & $113.72 \pm 36.96^{\# \#}$ & $105.16 \pm 28.12^{\# \#}$ \\
QFPD group & $154.45 \pm 36.07^{*}$ & $98.72 \pm 18.40$ \\
DXMS group & $146.01 \pm 25.20$ & $143.88 \pm 23.98^{*}$ \\
\hline
\end{tabular}

Compared with the blank control group, \# $\mathrm{P}<0.05$, \# $\mathrm{P}<0.01$; compared with the model group, * $\mathrm{P}<0.05$, ** $P<0.01$

As shown in Table 11, in BALF, the KL-6 concentration of model group was markedly higher than that of blank control group $(\mathrm{P}<0.01)$; compared with the model group, only the QFPD group could effectively reduce the $K L-6$ concentration $(P<0.05)$. In serum, model group significantly increased the KL-6 concentration $(P<0.01)$ compared with blank control group, while the medication groups significantly decreased the KL-6 concentration compared with model group $(P<0.05)$, and the degree of decrease was QFPD group > DXMS group.

Table 11

Comparison of BALF and serum $\mathrm{KL}-6$ concentration results of rats in each group $(\mathrm{U} / \mathrm{ml})$

\begin{tabular}{|lll|}
\hline Group & KL-6 in BALF & KL-6 in serum \\
\hline Blank control group & $69.46 \pm 14.12$ & $76.29 \pm 12.73$ \\
\hline Model group & $166.27 \pm 13.61^{\# \#}$ & $198.65 \pm 20.30^{\# \#}$ \\
\hline QFPD group & $143.64 \pm 25.58^{*}$ & $150.03 \pm 29.51^{\star *}$ \\
\hline DXMS group & $163.88 \pm 20.11$ & $168.34 \pm 18.31^{*}$ \\
\hline
\end{tabular}

Compared with the blank control group, \# $\mathrm{P}<0.05$, \# $\mathrm{P}<0.01$; compared with the model group, * $\mathrm{P}<0.05$, $\star * P<0.01$

As shown in Table 12, in BALF and serum, the CRP content of model group was obviously increased ( $<$ 0.01) compared with blank control group, however, the CRP content of administration groups decreased in different degree compared with model group $(P<0.05$ in BALF, $P<0.01$ in serum), and the degree of reduction was QFPD group > DXMS group in BALF, DXMS group > QFPD group in serum. 
Table 12

Comparison of BALF and serum CRP concentration results of rats in each group $(\mathrm{ng} / \mathrm{ml})$

\begin{tabular}{|lll|}
\hline Group & CRP in BALF & CRP in serum \\
\hline Blank control group & $70.85 \pm 2.18$ & $159.07 \pm 15.99$ \\
\hline Model group & $179.60 \pm 15.12^{\# \#}$ & $218.12 \pm 7.86^{\# \#}$ \\
\hline QFPD group & $103.90 \pm 20.62^{\star \star}$ & $166.87 \pm 16.43^{\text {** }}$ \\
\hline DXMS group & $116.81 \pm 29.39^{*}$ & $155.96 \pm 9.55^{\star *}$ \\
\hline
\end{tabular}

Compared with the blank control group, \# $\mathrm{P}<0.05$, \# $\mathrm{P}<0.01$; compared with the model group, ${ }^{*} \mathrm{P}<0.05$, ** $P<0.01$

\section{SOD vitality in serum}

As shown in Table 13, the SOD activity of model group was significantly lower than that of blank control group $(P<0.01)$, but the SOD activity of administration groups was obviously higher than that of the model group $(P<0.01)$, and the degree of increase was DXMS group > QFPD group.

Table 13

Comparison of serum SOD vitality results of rats in each group

(U/mgprot)

\begin{tabular}{|ll|}
\hline Group & SOD \\
\hline Blank control group & $10.82 \pm 0.63$ \\
\hline Model group & $7.18 \pm 0.66^{\# \#}$ \\
\hline QFPD group & $9.01 \pm 0.72^{\star *}$ \\
\hline DXMS group & $9.51 \pm 1.15^{* *}$ \\
\hline
\end{tabular}

Compared with the blank control group, \# $\mathrm{P}<0.05$, \# $\mathrm{P}<0.01$; compared with the model group, ${ }^{*}<0.05$, ** $P<0.01$

\section{Discussion}

COVID-19 pneumonia is an infectious disease caused by severe acute respiratory syndrome coronavirus 2 (SARS-CoV-2), most COVID-19 patients develop mild to moderate symptoms and recover without special treatment, but in some patients it may progress to pneumonia, ARDS and multiple organ dysfunction ${ }^{[8]}$. Although COVID-19 pneumonia conforms to the ARDS Berlin definition, it is a specific disease with a special phenotype ${ }^{[3]}$. The clinical manifestations were relatively mild in some COVID-19 patients, which was inconsistent with the severity of laboratory and imaging examinations. The onset time of ARDS associated with COVID-19 was 8-12 days, which was inconsistent with the ARDS Berlin 
criteria for defining a 1-week duration of attack ${ }^{[9]}$. Therefore, ARDS caused by COVID-19 is somewhat different from traditional ARDS, its manifestations can be seen as a combination of the two processes of viral pneumonia and ARDS ${ }^{[10]}$.

There are currently 4 methods for establishing ARDS animal models, of which the method established by endotoxin and oleic acid is the most widely used ${ }^{[11]}$. Studies have shown that OA mainly damages pulmonary vascular endothelial cells, leading to increased pulmonary vascular permeability and edema fluid exudation to promote the occurrence of ARDS; while LPS, as the main component of endotoxin, mainly triggers an uncontrolled inflammatory cascade reaction, which ultimately leads to lung inflammation, thereby promote the formation of ARDS [ ${ }^{12-14]}$. This experiment combined with OA and LPS to establish a "secondary strike" ARDS animal model which is closer to the clinical development of ARDS caused by COVID-19 pneumonia in the pathogenesis and pathological changes. After modeling, rats in the model group showed shortness of breath, increased heart rate, increased $\mathrm{PaCO}_{2}$, decreased $\mathrm{PaO}_{2}$ and $\mathrm{SaO}_{2}$, increased $\mathrm{LI}$ and $\mathrm{LPI}$ as well as increased of BALF and serum pro-inflammatory factors (TNF- $a$, IL-1 $\beta$, IL-8, IL-6) and CRP content, decreased of anti-inflammatory factor IL-10 content, in addition, lung injury can be seen under light microscope, indicating that the modeling was successful. Compared with the model group, the administration groups alleviated various symptoms to varying degrees, indicating that QFPD and dexamethasone have therapeutic effects on ARDS.

According to some studies, cytokines storm will occur in the critically ill patients with COVID-19 pneumonia, and a large number of cytokines will be released, including IL-1 $\beta, I L-6, I L-8, I L-10$ and TNF-a etc, which will result in serious inflammatory reaction and related complications. Virus invasion leads to the loss of negative feedback of immune regulation, and the abnormal increase of various cytokines, which will cause diffuse damage to pulmonary capillary endothelial cells and alveolar epithelial cells, and a large amount of exudate will block the airway, leading to ARDS. The patient's immune profile revealed impaired homeostasis in various immune cells, including reduced totals of $T$ lymphocytes, $B$ lymphocytes, monocytes, and natural killer cells, on the contrary, the number of neutrophile granulocyte and CRP levels were significantly increased. Excessive inflammation eventually turns into an immunosuppression state, which may play a crucial role in the deterioration of the disease ${ }^{[15,16]}$. The study found that IL-10 levels in patients with ARDS reached a peak on the first day and slowly dropped to an undetectable level after 21 days, suggesting that IL-10 has a significant anti-inflammatory effect during an ARDS attack ${ }^{[17]}$. In this experiment, it was observed that the IL-10 content of model group was remarkably lower than that of blank control group after 7 days of modeling. In BALF and serum, both QFPD group and dexamethasone group could increase the content of IL-10 compared with model group, which is consistent with the content of the above literature. CRP refers to some proteins that rise sharply in the plasma when the body is infected or tissue damaged, it can eliminate pathogenic microorganisms and damaged, necrotic, apoptotic tissue cells to play an important protective role in the body's innate immunity. The significant increase in neutrophils, CRP and inflammatory factors at the same time suggests that the body has produced an excessive inflammatory response. 
$\mathrm{TXB}_{2}$ and 6Keto-PGF1a are the metabolites of Thromboxane $\mathrm{A}_{2}\left(\mathrm{TXA}_{2}\right)$ and prostaglandin $\mathrm{I}_{2}\left(\mathrm{PGI}_{2}\right)$, respectively. $\mathrm{TXB}_{2}$ is mainly synthesized and released by platelet microsomes, which has the functions of constricting blood vessels, accumulating platelets, and causing atherosclerosis, while 6 Keto-PGF1a as an alternative detection index of $\mathrm{PGI}_{2}$, contrary to the $\mathrm{TXB}_{2}$ effect, it has strong anti-platelet aggregation effect ${ }^{[18]}$. Studies have found that plasma $\mathrm{TXB}_{2}$, 6Keto-PGF1a levels in ARDS patients are obviously higher, and there is a statistical correlation between high $\mathrm{TXB}_{2}$ and ARDS, but the content of $\mathrm{TXB}_{2}, 6$ KetoPGF1a is unbalanced, and the value of $\mathrm{TXB}_{2}$ is higher ${ }^{[19]}$. Earlier research and related autopsy reports suggest that COVID-19 pneumonia is accompanied by fibrin thrombosis and extensive extracellular fibrin deposition ${ }^{[20]}$. On the other hand, the consumption of coagulation factors can lead to the risk of serious bleeding complications and may eventually cause disseminated intravascular coagulation ${ }^{[21]}$. Therefore, regulating the balance of $\mathrm{TXB}_{2}$, 6Keto-PGF1a plays an important role in the clinical treatment of ARDS.

Alveolar epithelial injury and increased vascular permeability are important pathological features of ARDS. KrebsvondenLungen- 6 (KL-6) mainly exists on the surface of type II alveolar epithelial cell and is dramatically increased in proliferative, stimulated or damaged type II pneumocytes. A series of studies have shown that KL-6 has certain sensitivity and specificity in diagnosing and judging ARDS prognosis $[22,23]$. The autopsy report on COVID-19 patients stated that from histological point of view, diffuse alveolar damage appeared in the lungs, including alveolar epithelial cell injury, hyaline membrane formation and hyperplasia of type II pneumocytes ${ }^{[24]}$. Compared with healthy subjects, patients with COVID-19 pneumonia have elevated serum KL-6 levels, which can be used as a good marker for assessing the severity of interstitial lung disease (ILD) in COVID-19 infection, and the serum level of KL-6 may be of great significance for diagnosis, prognosis and treatment evaluation in COVID-19 infections [25]

Under normal conditions, the lung department produces a certain amount of oxygen-free radicals (ROS), and the lung has an effective ROS scavenging system to make its production and clearance in a balanced state. However, when the lung tissue suffers from serious infection, trauma and other high-risk factors, the balance between the production and release of free radicals is destroyed, ROS cannot be cleared in time, thus damaging the lung tissue cells ${ }^{[26]}$. ROS is widely believed to play a very important role in ARDS pathogenesis. In the body of patients with ARDS, the production of peroxides increases, the elimination ability decreases, and the antioxidant system is severely inhibited ${ }^{[27]}$. Superoxide dismutase (SOD) is an antioxidant metalloenzyme that protects cells by reducing the accumulation of ROS in cells. Therefore, enhancing the vitality of the SOD has a protective effect on ARDS.

\section{Conclusions}

In summary, after treatment with QFPD and dexamethasone, the rats in the model group have improved pulmonary edema, reduced inflammatory cell infiltration, and reduced lung index and lung permeability index, besides, $\mathrm{PaCO}_{2}$ decreased, $\mathrm{PaO}_{2}$ and $\mathrm{SaO}_{2}$ increased, indicating that QFPD and dexamethasone 
have protective effects on ARDS induced by OA + LPS. This may be related to reducing the content of CRP, IL-1 $\beta, I L-6, I L-8, T N F-a$ and increasing the content of IL-10 to regulate the balance of inflammatory factors and inhibit excessive inflammation; reducing the content of $\mathrm{TXB}_{2}$ and increasing the content of 6Keto-PGF1a to inhibit the formation of microthrombosis in the lung and the occurrence of diffuse intravascular coagulation; at the same time reducing the content of KL-6, increasing the vitality of SOD to reduce the damage of lung tissue cells. Comprehensive comparison of the results in BALF and serum, it can be concluded that QFPD has a more obvious effect than dexamethasone.

\section{Abbreviations}

COVID-19: Coronavirus Disease-2019; ARDS: Acute respiratory impoverishment syndrome; 2019-nCoV: 2019 novel coronavirus; TCM: Traditional Chinese medicine; OA: Oleic acid; LPS: Lipopolysaccharide; LI: Lung index; LPI: Lung permeability index; $\mathrm{PaO}_{2}$ : Partial arterial oxygen pressure; $\mathrm{PaCO}_{2}:$ Partial arterial carbon dioxide pressure; $\mathrm{SaO}_{2}$ : Arterial oxygen saturation; TNF-a: Tumor necrosis factor-a; IL-: Interleukin; $\mathrm{TXB}_{2}$ : Thromboxane $\mathrm{B}_{2}$; 6-keto-PGF1a: 6-keto-prostaglandin F1a; KL-6: Kerbs von lungren 6 antigen; CRP: C-reactive protein; SOD: Superoxide dismutase; OD: Optical density; HE: Hematoxylin and eosin; SARS-CoV-2: Severe acute respiratory syndrome coronavirus 2; $\mathrm{TXA}_{2}$ : Thromboxane $\mathrm{A}_{2} ; \mathrm{PGI}_{2}$ : prostaglandin $\mathrm{I}_{2}$; ILD: Interstitial lung disease.

\section{Declarations}

\section{Ethics approval and consent to participate}

This study was approved by the Animal Ethics Committee of Chinese People's Liberation Army Western Theater General Hospital.

\section{Consent for publication}

All authors critically reviewed the content of the manuscript. The consent for publication was obtained from all authors.

\section{Availability of data and materials}

The datasets used and/or analyzed during the current study are available from the corresponding author on reasonable request.

\section{Competing interests}

The authors declare that they have no competing interests.

\section{Funding}


This work was supported by the Fundamental Research Funds for the Central Universities (Study on Pharmacodynamics and in vivo Process of Chinese Herbal Compound in Treatment of ARDS Caused by Covid-19 Syndrome, No. A0920502052001-10).

\section{Authors' contributions}

$X W$ and $X Y W$ conceived and designed this study. ZXH and XYW performed the experiments. ZXH and XYW analyzed data. ZXH embellished the figures and drafted the manuscript. JYW and XW offered help and participated in experimental discussions. All authors read and approved the final manuscript.

\section{Acknowledgements}

Not applicable.

\section{References}

1. Matthay MA, Zemans RL, Zimmerman GA, Arabi YM, Beitler JR, Mercat A, et al. Acute respiratory distress syndrome. Nat Rev Dis Primers. 2019;5(1):18.

2. Matthay LBW. MA. The acute respiratory distress syndrome. N Engl J Med. 2000;342(18):1334-49.

3. Gattinoni L, Chiumello D, Rossi S. COVID-19 pneumonia: ARDS or not? Crit Care. 2020;24(1):154.

4. Nahama A, Ramachandran $\mathrm{R}$, Cisternas AF, Ji $\mathrm{H}$. The role of afferent pulmonary innervation in ARDS associated with COVID-19 and potential use of resiniferatoxin to improve prognosis: A review. Med Drug Discov. 2020;5:100033.

5. Chen J, Wang YK, Gao Y, Hu LS, Yang JW, Wang JR, et al. Protection against COVID-19 injury by qingfei paidu decoction via anti-viral, anti-inflammatory activity and metabolic programming. Biomed Pharmacother. 2020;129:110281.

6. Shi N, Liu B, Liang N, Ma Y, Ge Y, Yi H, et al. Association between early treatment with Qingfei Paidu decoction and favorable clinical outcomes in patients with COVID-19: A retrospective multicenter cohort study. Pharmacol Res. 2020;161:105290.

7. MIL-OSI United Kingdom: expert reaction to the RECOVERY trial reporting that dexamethasone reduces death by up to one third in hospitalised COVID-19 patients with severe respiratory complications. 2020.

8. Singhal T. A Review of Coronavirus Disease-2019 (COVID-19). Indian J Pediatr. 2020;87(4):281-6.

9. Li X, Ma X. Acute respiratory failure in COVID-19: is it "typical" ARDS? Crit Care. 2020;24(1):198.

10. Gibson PG, Qin L, Puah SH. COVID-19 acute respiratory distress syndrome (ARDS): clinical features and differences from typical pre-COVID-19 ARDS. Med J Aust. 2020;213(2):54-6. e1.

11. Matute-Bello G, Frevert CW, Martin TR. Animal models of acute lung injury. Am J Physiol Lung Cell Mol Physiol. 2008;295(3):L379-99.

12. Goncalves-de-Albuquerque CF, Silva AR, Burth P, Castro-Faria MV, Castro-Faria-Neto HC. Acute Respiratory Distress Syndrome: Role of Oleic Acid-Triggered Lung Injury and Inflammation. 
Mediators Inflamm. 2015;2015:260465.

13. Zhou Z, Kozlowski J, Schuster DP. Physiologic, biochemical, and imaging characterization of acute lung injury in mice. Am J Respir Crit Care Med. 2005;172(3):344-51.

14. Qin M, Qiu Z. Changes in TNF-alpha, IL-6, IL-10 and VEGF in rats with ARDS and the effects of dexamethasone. Exp Ther Med. 2019;17(1):383-7.

15. Zhong J, Tang J, Ye C, Dong L. The immunology of COVID-19: is immune modulation an option for treatment? The Lancet Rheumatology. 2020;2(7):e428-e36.

16. Pasrija R, Naime M. The deregulated immune reaction and cytokines release storm (CRS) in COVID19 disease. Int Immunopharmacol. 2021;90:107225.

17. Park WY, Goodman RB, Steinberg KP, Ruzinski JT, Radella IIF, Park DR, et al. Cytokine balance in the lungs of patients with acute respiratory distress syndrome. Am J Respir Crit Care Med. 2001;164(10):1896-903.

18. Jiang ZH, Zhong G, Wang W, fan EE, Jia J, Lu GR. Q, et al. The changes of thromboxane B2 (TXB2) and 6-keto-prostaglandin F1 alpha(6-keto-PGF1 alpha) in the lungs of rats drowned in hypothermicsea-water. Zhonghua Lao Dong Wei Sheng Zhi Ye Bing Za Zhi. 2002;20(1):29-31.

19. Deby-Dupont G, Braun M, Lamy M, Deby C, Pincemail J, Faymonville ME, et al. Thromboxane and prostacyclin release in adult respiratory distress syndrome. Intensive Care Med. 1987;13(3):167-74.

20. Samkari HA, Karp Leaf RS, Dzik WH, Carlson JCT, Fogerty AE, Waheed A, et al. COVID-19 and coagulation bleeding and thrombotic manifestations of SARS-CoV-2 infection. Blood. 2020;136(4):489-500.

21. Singh P, Schwartz RA. Disseminated intravascular coagulation: A devastating systemic disorder of special concern with COVID-19. Dermatol Ther. 2020;33(6):e14053.

22. Ishizaka A, Matsuda T, Albertine KH, Koh H, Tasaka S, Hasegawa N, et al. Elevation of KL-6, a lung epithelial cell marker, in plasma and epithelial lining fluid in acute respiratory distress syndrome. Am J Physiol Lung Cell Mol Physiol. 2004;286(6):1088-94.

23. Kondo T, Hattori N, Ishikawa N, Murai H, Haruta Y, Hirohashi N, et al. KL-6 concentration in pulmonary epithelial lining fluid is a useful prognostic indicator in patients with acute respiratory distress syndrome. Respir Res. 2011;12(1):32.

24. Tian S, Xiong Y, Liu H, Niu L, Guo J, Liao M, et al. Pathological study of the 2019 novel coronavirus disease (COVID-19) through postmortem core biopsies. Mod Pathol. 2020;33(6):1007-14.

25. Frix AN, Schoneveld L, Ladang A, Henket M, Duysinx B, Vaillant F, et al. Could KL-6 levels in COVID-19 help to predict lung disease? Respir Res. 2020;21(1):309.

26. Kellner M, Noonepalle S, Lu Q, Srivastava A, Zemskov E, Black SM. ROS Signaling in the Pathogenesis of Acute Lung Injury (ALI) and Acute Respiratory Distress Syndrome (ARDS). Adv Exp Med Biol. 2017;967:105-37.

27. Metnitz PG, Bartens C, Fischer M, Fridrich P, Steltzer H, Druml W. Antioxidant status in patients with acute respiratory distress syndrome. Intensive care medicine. 1999;25(2):180-5. 


\section{Figures}
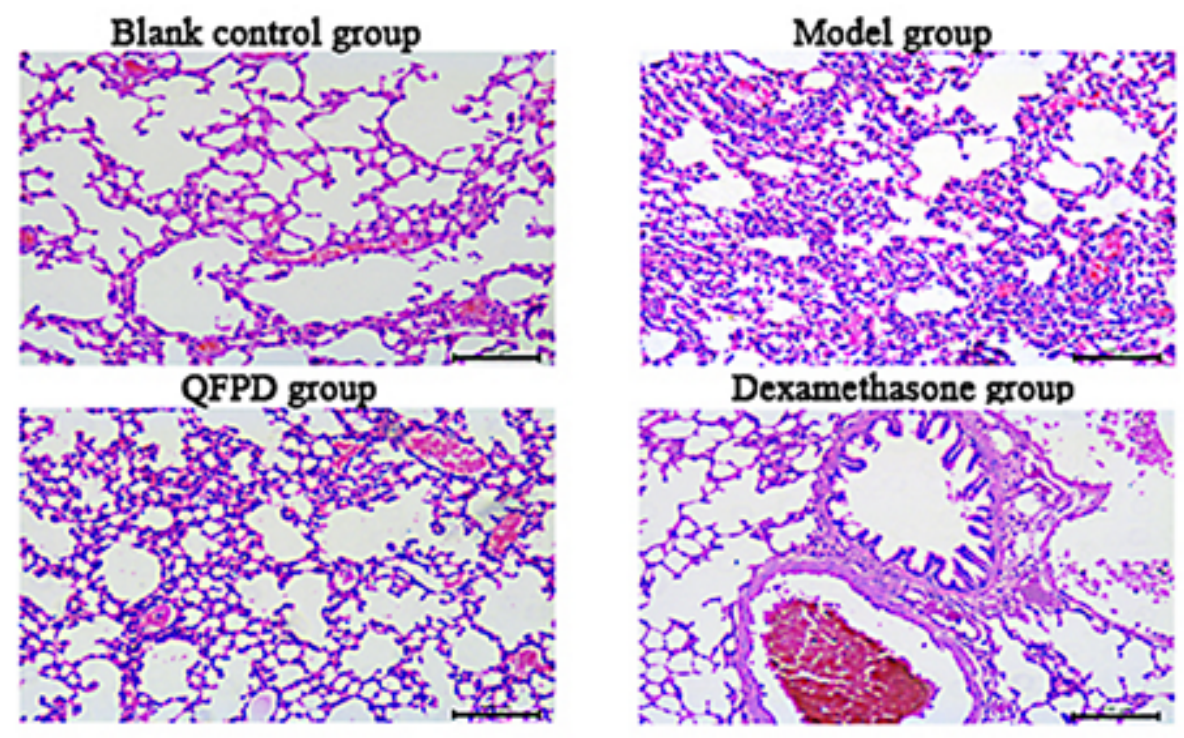

Figure 1

Pathological conditions of lung tissues in each group (HE staining, 400 times).

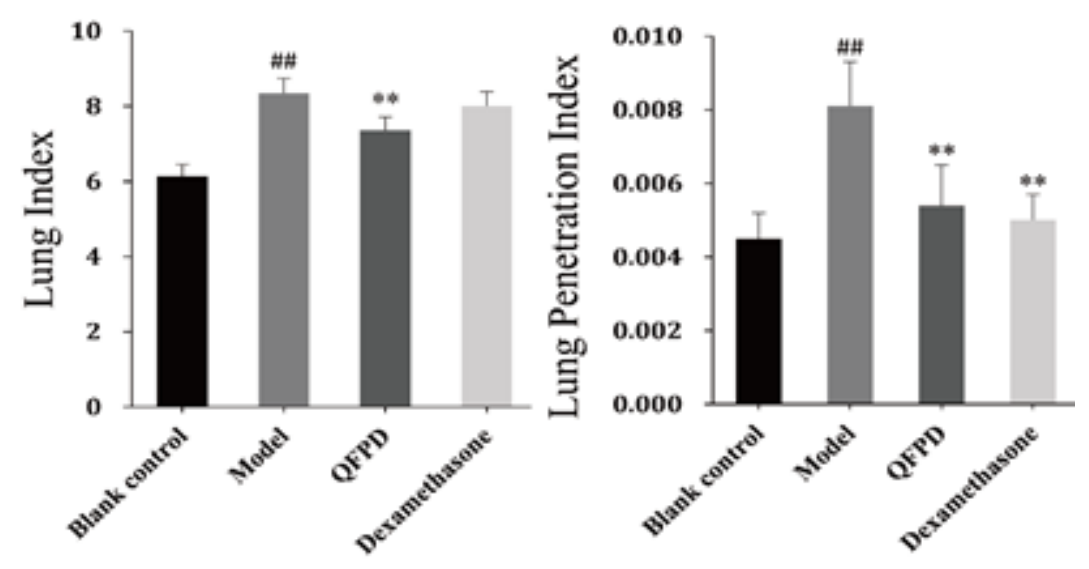

Figure 2

Comparison of blood gas analysis results in each group 

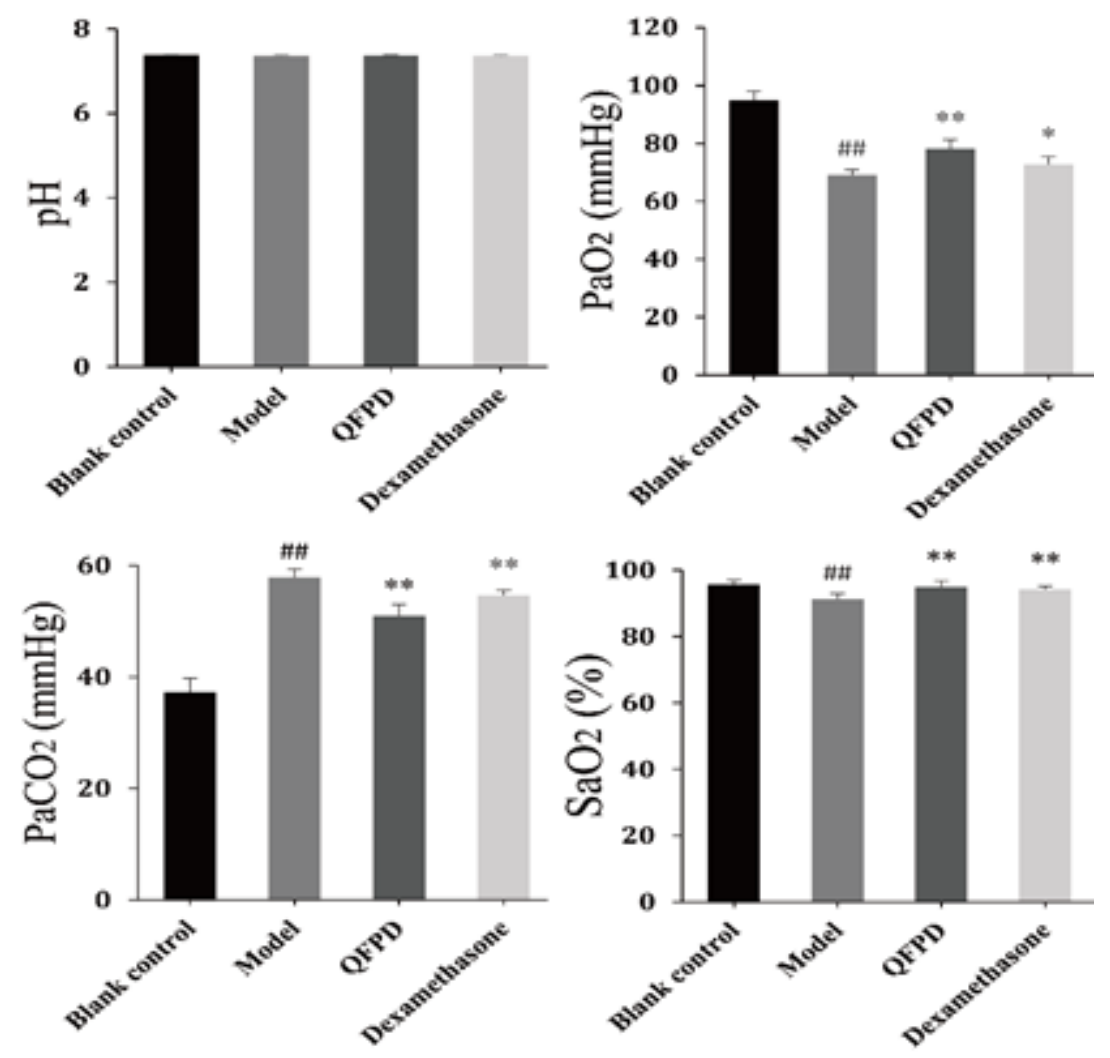

Figure 3

Comparison of blood gas analysis results in each group
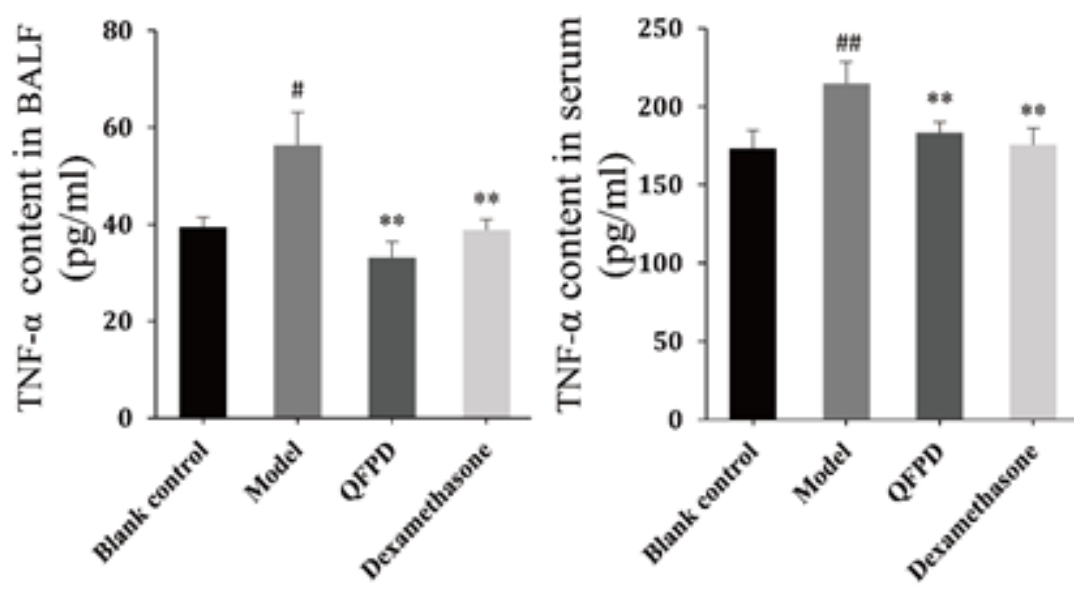

Figure 4

Comparison of BALF and serum TNF-a concentration results in each group 


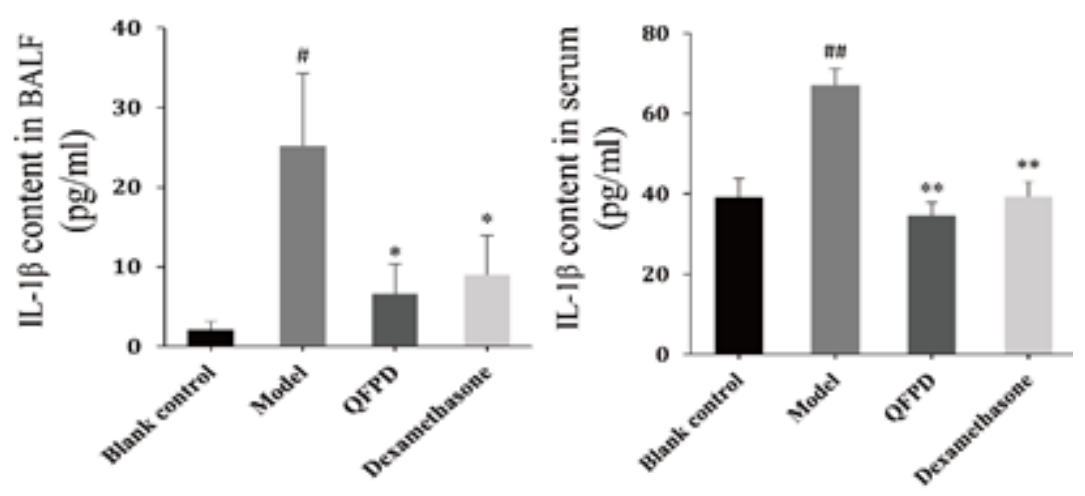

Figure 5

Comparison of BALF and serum IL-1 $\beta$ concentration results in each group

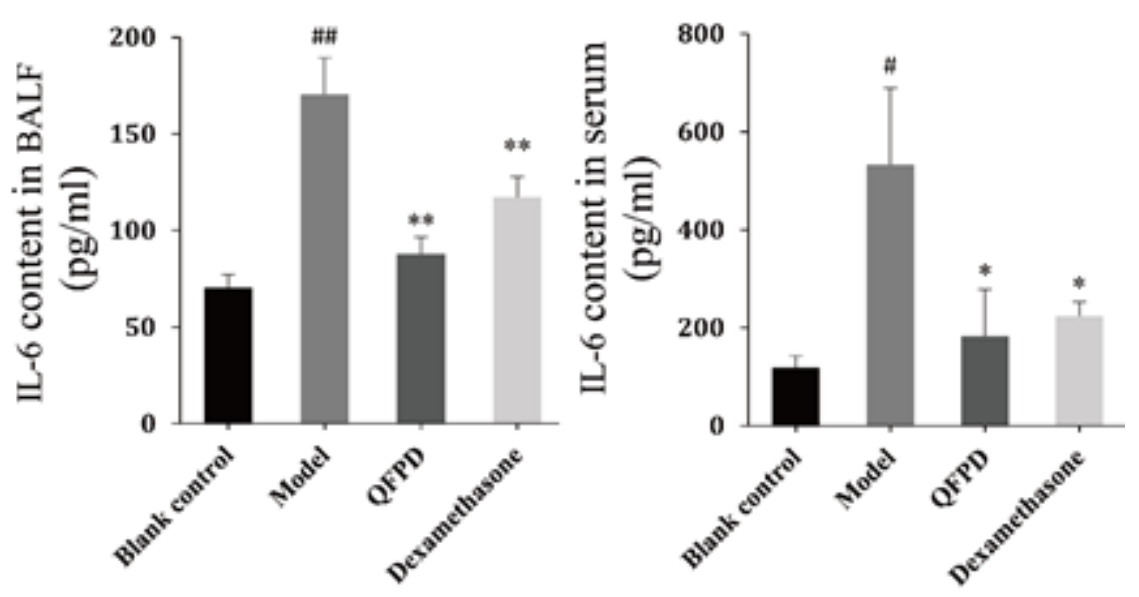

Figure 6

Comparison of BALF and serum IL-6 concentration results of rats

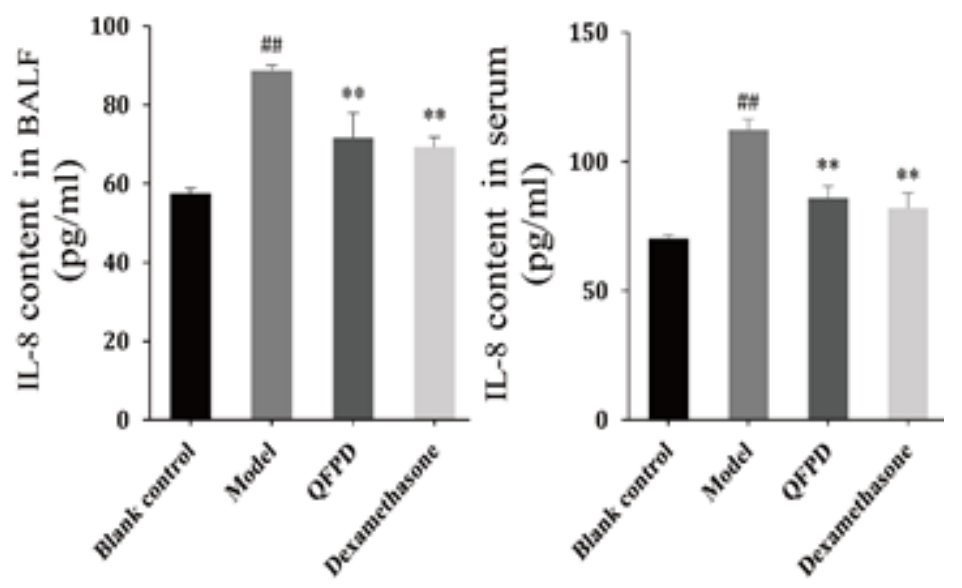

Figure 7

Comparison of BALF and serum IL-8 concentration results of rats in each group 


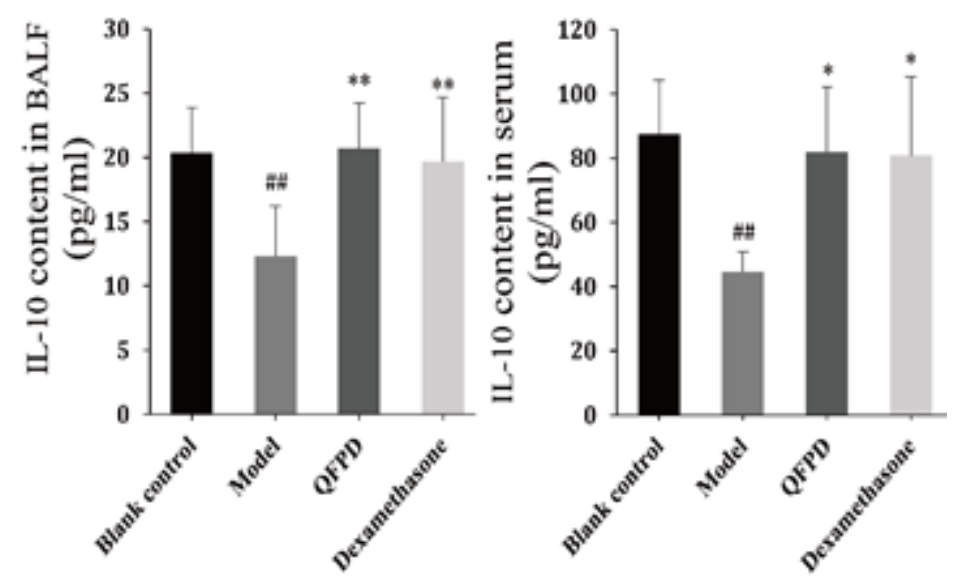

Figure 8

Comparison of BALF and serum IL-10 concentration results of rats in each group

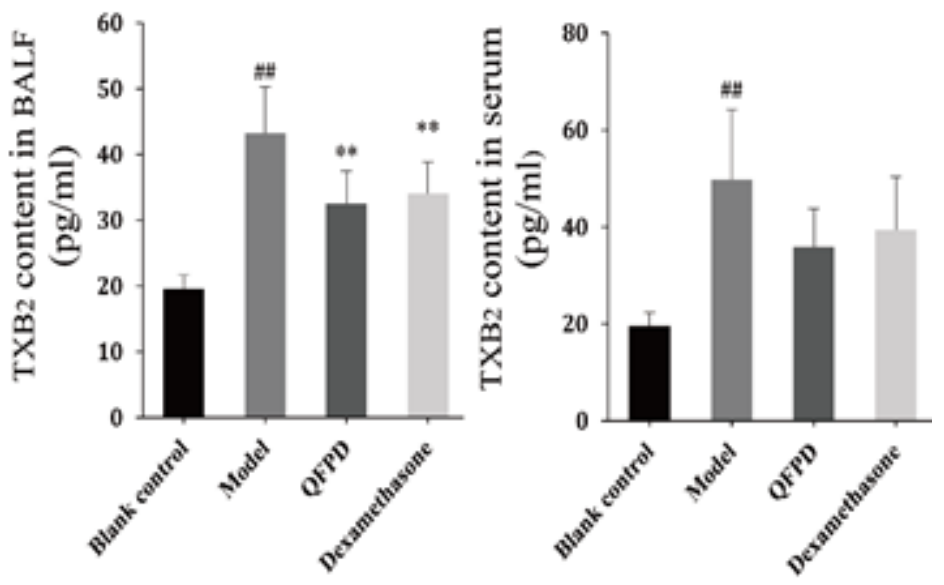

Figure 9

Comparison of BALF and serum TXB2 concentration results of rats in each group
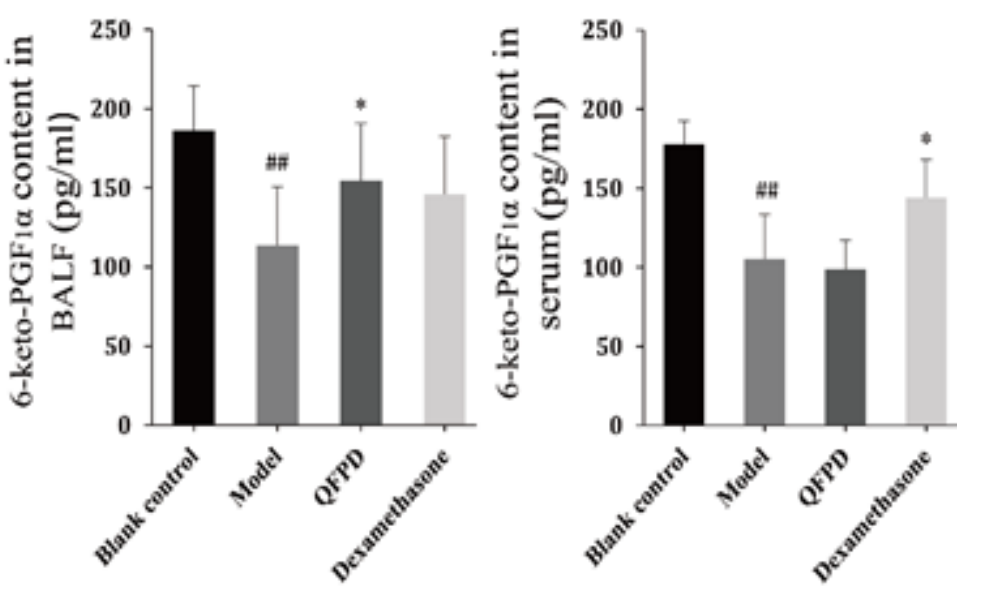

Figure 10 
Comparison of BALF and serum 6- keto-PGF1 a concentration results of rats in each group

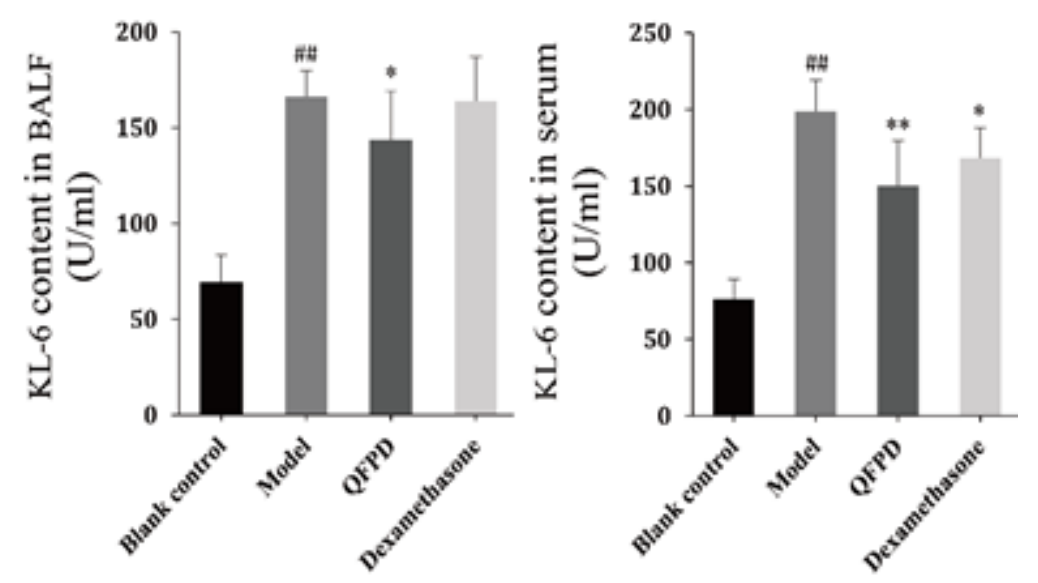

Figure 11

Comparison of BALF and serum KL-6 concentration results of rats in each group

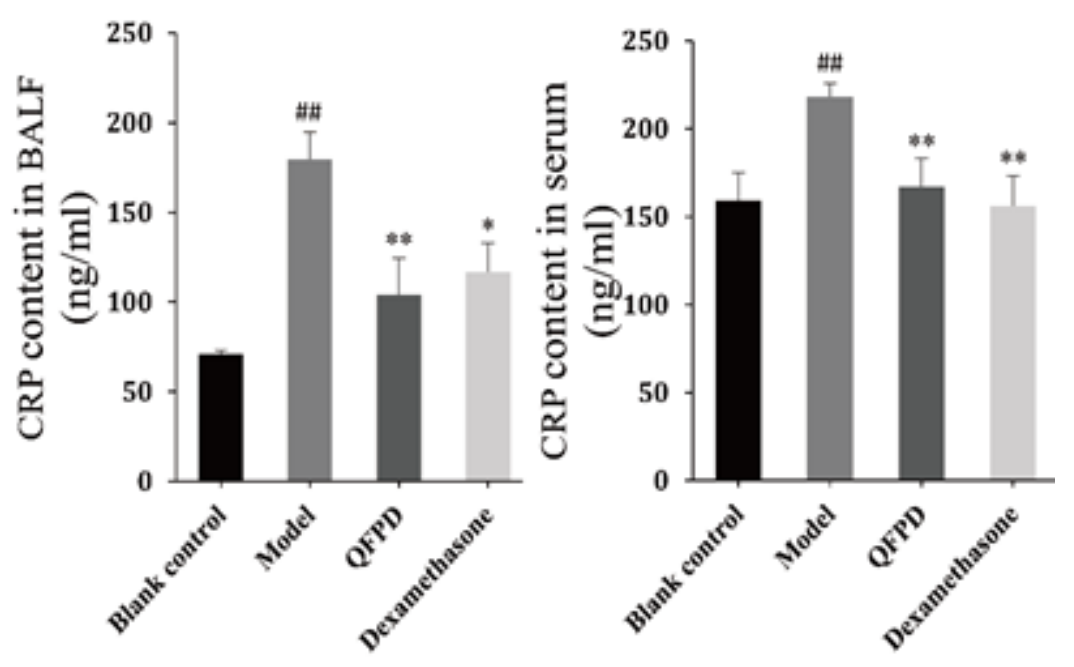

Figure 12

Comparison of BALF and serum CRP concentration results of rats in each group

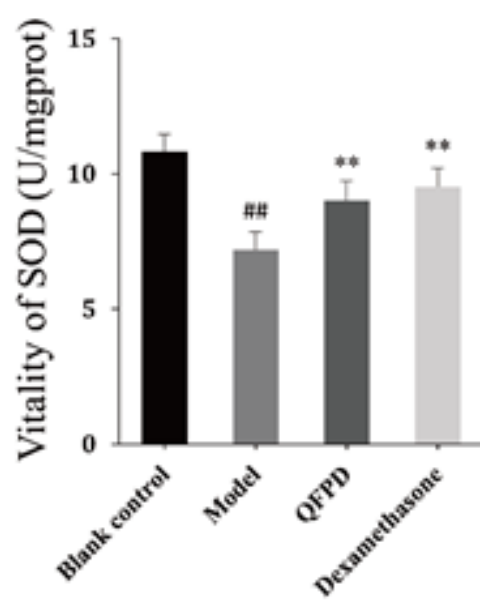


Figure 13

Comparison of serum SOD vitality results of rats in each group 